\section{Production of a Heterozygous Mutant Cell Line by Homologous Recombination (Single Knockout)}

Gene targeting by homologous recombination allows the introduction of specific mutations into any cloned gene. In the method described here, the gene of interest is inactivated by interrupting its coding sequence with a positive selectable marker (e.g., neo). Expression of neo is obtained by including the phosphoglycerate kinase (PGK) promoter in the construct. To enrich for clones in which the target gene has undergone homologous recombination over those in which random integration of the construct has occurred, a negative selectable marker, herpes simplex virus thymidine kinase (HSV-TK), is included in the construct outside the region of homology to the target gene. Depending upon the target gene, it may be easier to assemble the construct by adding the neo and $T K$ genes to the cloned target gene or by adding two fragments of the target gene to a plasmid containing the neo and TK genes (e.g., pNTK; Fig. 4.30.1).

If the Cre-loxP system (UNIT 4.29) is to be used for removing the selectable marker, or for tissue-specific or temporally controlled knockout, then a construct already containing loxP sites flanking the marker is more convenient (e.g., pTKLNL; Fig. 4.30.2A). If selection for loss of selectable marker is desired, a construct that also contains a negative selectable marker can be used (e.g., pTKLNCL; Fig. 4.30.2B).

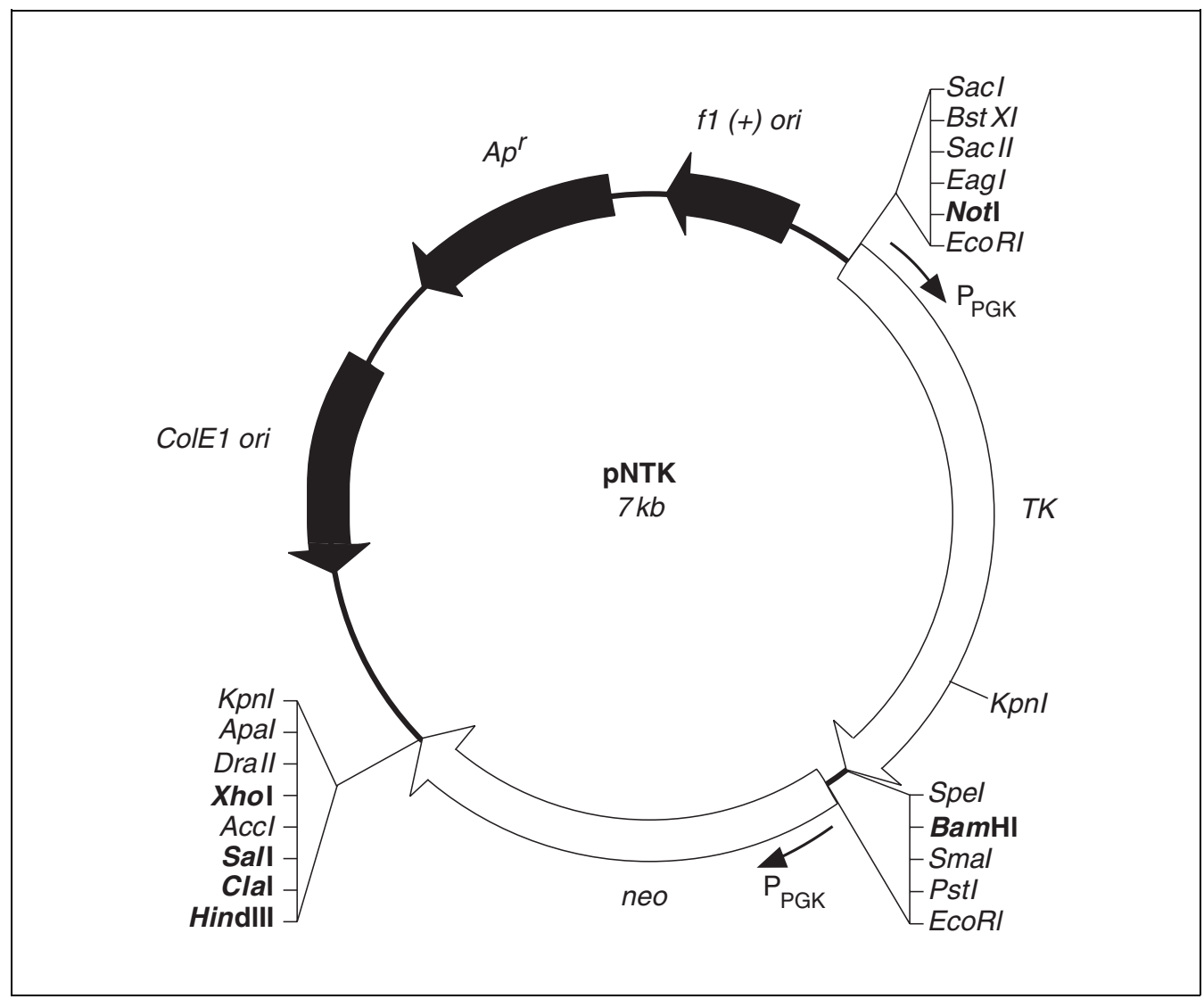

Figure 4.30.1 pNTK vector. Both the neo and TK genes are driven by a PGK promoter ( $\left.P_{\mathrm{PGK}}\right)$ that is expressed in ES cells. Unique restriction enzyme sites that are useful are indicated in bold. One genomic fragment can be cloned into the $B a m H I$ site. A second genomic fragment can be cloned into the HindIII, Clal, Sall, Xhol sites. A site should be preserved that will linearize the construct, leaving the majority of plasmid vector sequences attached to the TK gene (e.g., Xhol).

Contributed by Richard Mortensen

Current Protocols in Neuroscience (2002) 4.30.1-4.30.11

Copyright $\odot 2002$ by John Wiley \& Sons, Inc.
Gene Cloning, Expression, and Mutagenesis

\subsection{1}

Supplement 21 
A

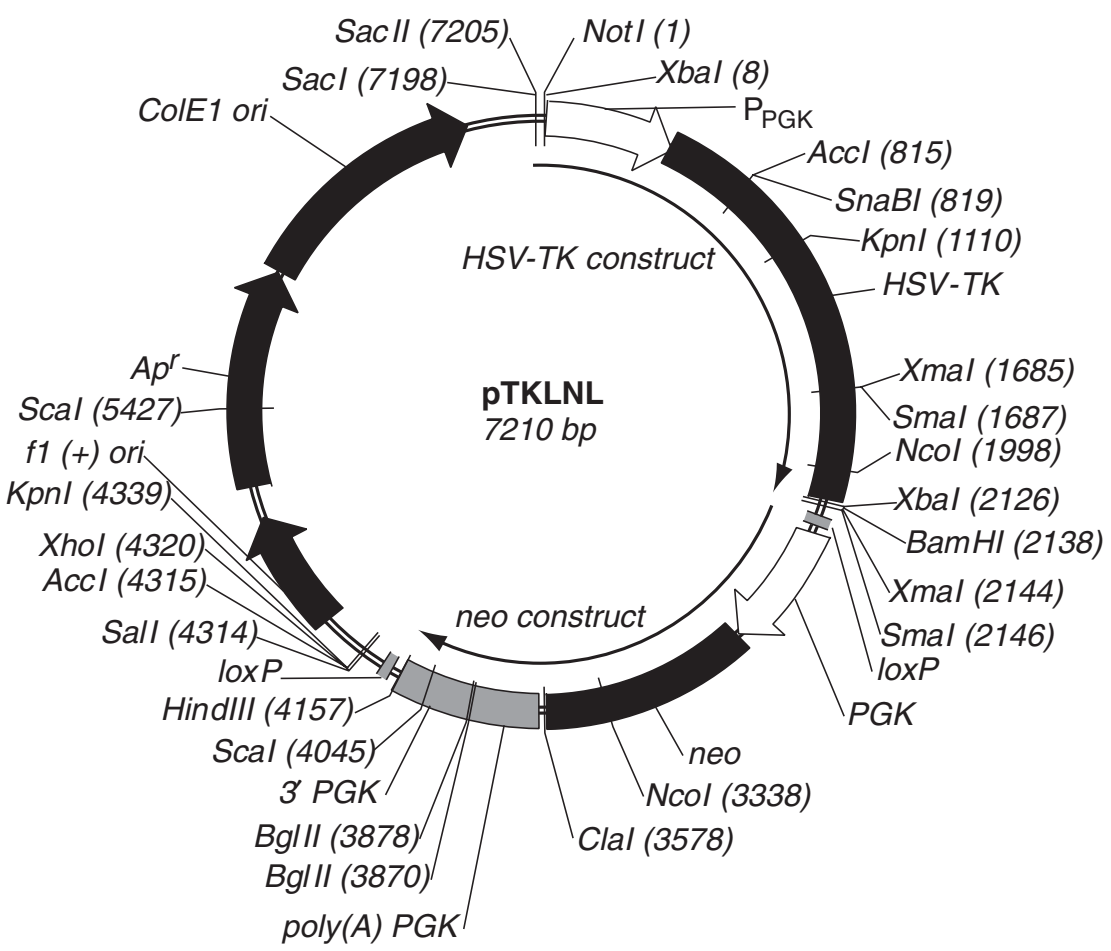

B

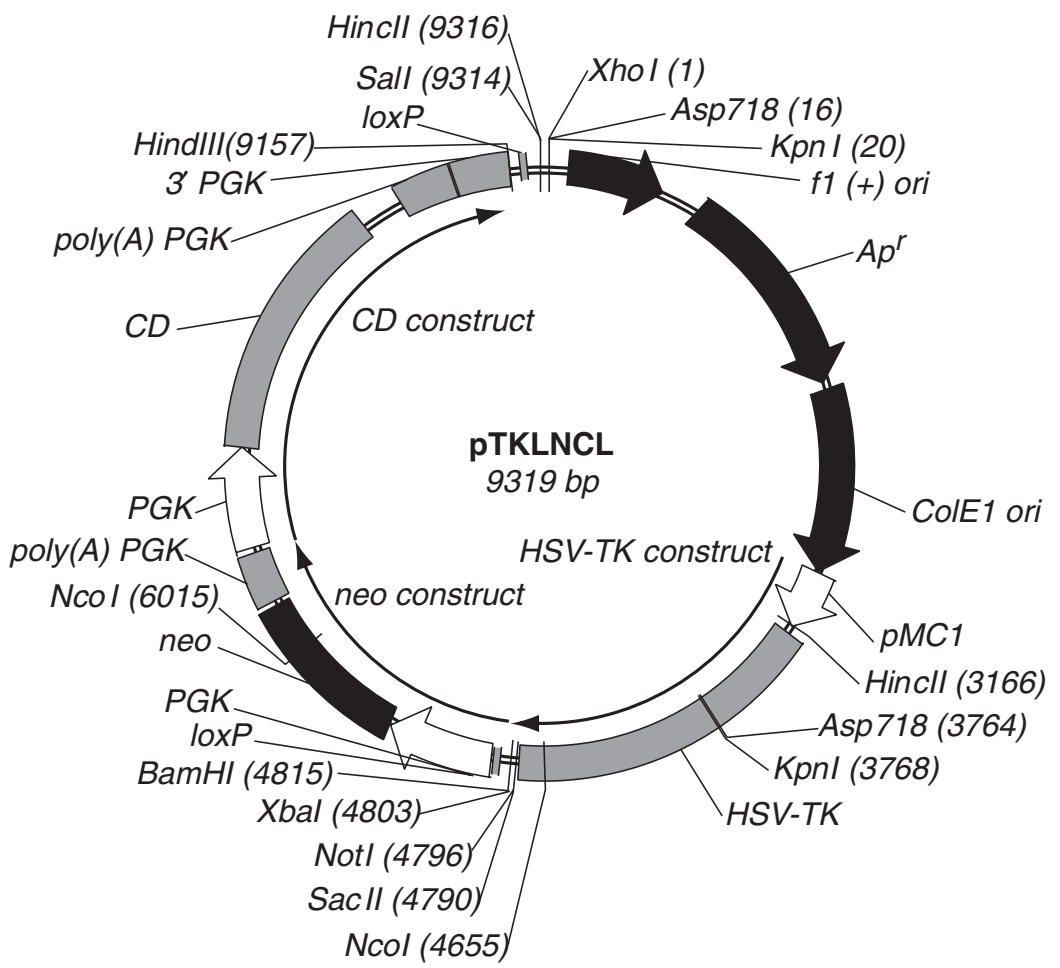

Production of a Heterozygous Mutant Cell Line

Figure 4.30.2 Constructs containing loxP sites surrounding a positive selectable marker, neo (A), or both a positive and a negative selectable marker, neo and cytosine deaminase $(C D ; \mathbf{B})$. Constructs can be made by insertion of homologous sequences in unique restriction sites outside the loxP sites. If conditional targeting constructs are desired (as in Fig. 4.29.7), a third loxP site can be inserted into the region of homology and then the two regions of homology inserted into the vectors. Another version of these plasmids is also available with the $T K$ and $C D$ reversed (Milstone et al., 1999).

4.30.2 


\section{STRATEGIC PLANNING}

Figure 4.30.3 illustrates the production, selection, and identification of targeted gene disruption by homologous recombination. A replacement targeting construct requires the assembly of several different DNA sequences:

1. A genomic clone (preferably $>10 \mathrm{~kb}$ ) of the gene of interest, generally encoded on a bacteriophage or cosmid clone containing homologous sequences to be included in the construct. DNA isogenic to the ES cells (i.e., derived from the same animal strain) is preferred but not essential. An alternative for genes of sufficient size, and regions for which mouse sequences are known, is long PCR (Cheng et al., 1994). This

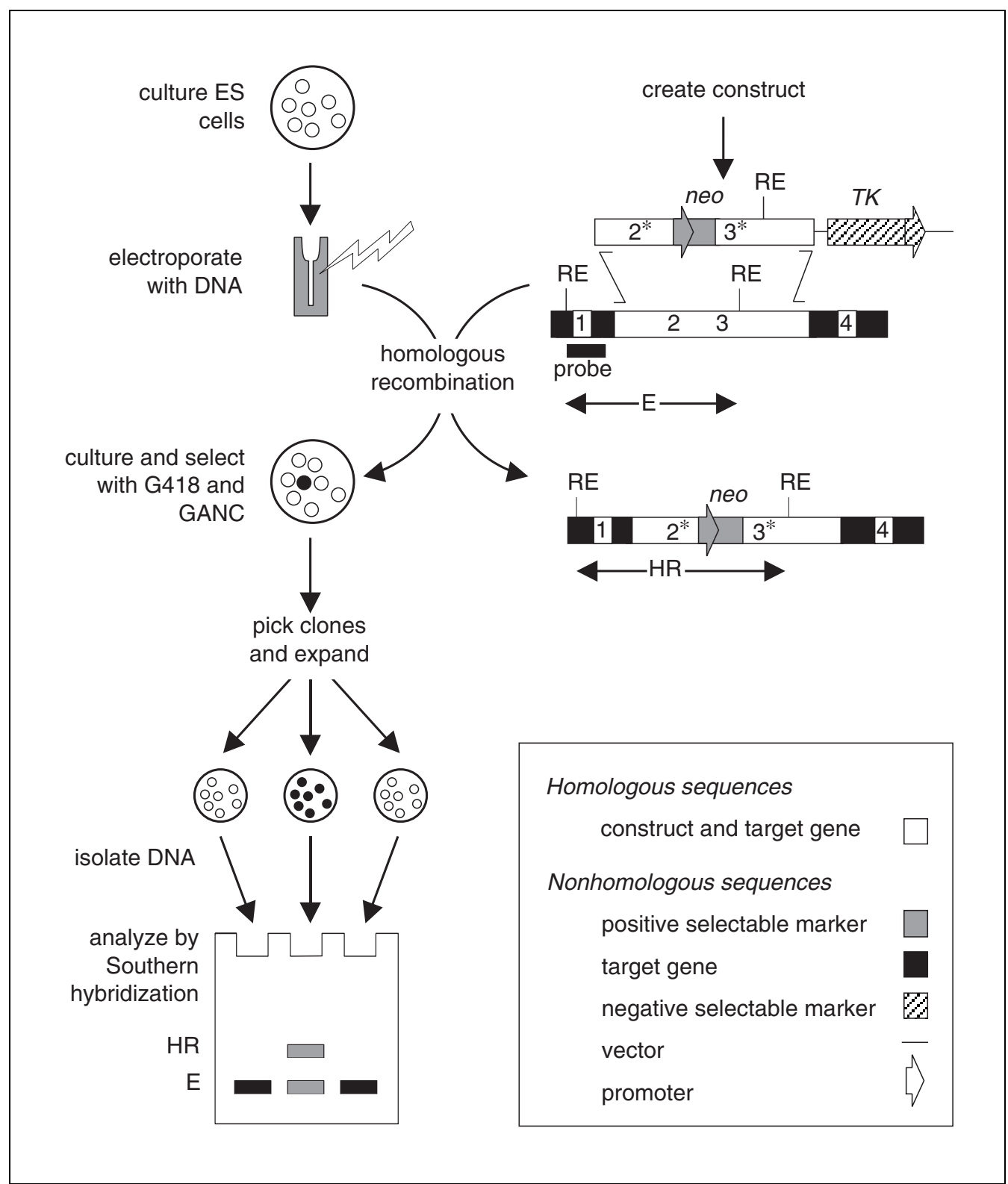

Figure 4.30.3 Production, selection, and identification of targeted gene disruption by homologous recombination. An example of a restriction enzyme site $(\mathrm{RE})$ and hybridization probe that can be used to identify cells in which homologous recombination has occurred (shaded colony) is shown. The predicted size of the restriction fragment generated from an unaltered target gene $(E)$ and a target gene that has undergone homologous recombination (HR) is shown. If equal amounts of DNA are present in the lanes of the Southern blot, the intensity of each of the two hybridizing fragments from the DNA of a homologous recombinant clone will be half of the intensity of the hybridizing fragment from unaltered clones.

Gene Cloning, Expression, and Mutagenesis

\subsection{3}

Supplement 21 
approach works for many genes as long as they have large enough introns, and is particularly convenient when the intron-exon structure of the gene is known. Long PCR may introduce mutations, which may decrease homologous recombination rates just as nonisogenic DNA can. In addition, the mutations may occur in important parts of the gene; this risk makes the approach less suitable for conditional knockouts or subtle mutations.

2. Additional cloned target-gene DNA sequences not included in the construct, to be used as a hybridization probe to identify homologous recombinants. This probe can often be isolated from the same bacteriophage or cosmid clone that provided the homologous sequences included in the construct. The hybridization probe will hybridize with either an unaltered target gene or a target gene that has undergone homologous recombination, but will not hybridize with a construct that entered the genome by random integration.

3. A positive selectable marker, such as the gene encoding neomycin phosphotransferase (neo) or hygromycin-B-phosphotransferase (hyg), which is used to disrupt the target gene. If a homozygous mutant cell line is an ultimate goal, it is recommended that the neo coding sequence contain the point mutation that decreases the phosphotransferase activity (Yenofsky et al., 1990). Using the PGK promoter and the wild-type neo gene may result in cells containing a single neo gene that are resistant to $>10 \mathrm{mg} / \mathrm{ml} \mathrm{G} 418$, thus precluding the use of higher G418 concentration to isolate clones containing two neo genes (see CPMB UNIT 23.6).

4. A negative selectable marker such as HSV-TK, which is used to enrich for ES cell clones in which homologous recombination has occurred in the target gene over clones in which random integration of the construct has occurred.

BASIC PROTOCOL

Production of a Heterozygous Mutant Cell Line

\section{GENE TARGETING IN EMBRYONIC STEM CELLS}

The basic protocol is divided into three parts. First, it outlines the assembly of a replacement targeting construct and considerations in choosing its exact structure. Second, it briefly describes the culture of embryonic stem (ES) cells and the method for introducing the construct DNA into ES cells. A more detailed description of culturing ES cells and maintaining their undifferentiated state is found in CPMB UNITS $23.2 \& 23.3$. Third, it outlines the method for identifying clones in which the target gene has been altered by homologous recombination. The resulting homologous recombinants are heterozygous (one allele of the target gene is altered by homologous recombination and one allele is normal) and can be used to produce transgenic murine lines or to produce homozygous mutant cell lines (in which both alleles of the target gene are altered; CPMB UNIT 23.6).

\section{Materials}

Target gene from genomic library isogenic with ES cell line (e.g., $129 \mathrm{SV}$ library; Stratagene)

Plasmid vector (e.g., pNTK, available from R. Mortensen; see Fig. 4.30.1)

$95 \%$ ethanol

Sterile $\mathrm{H}_{2} \mathrm{O}$

Embryonic stem (ES) cells (see CPMB UNITS $23.2 \& 23.3$ and APPENDIX $1 A$ in this manual; ATCC)

ES/LIF medium (see recipe)

Trypsin/EDTA: $0.25 \%$ (w/v) trypsin/1 mM EDTA (20 mM HEPES, $\mathrm{pH} 7.3$, optional)

ES medium (see recipe)

Electroporation buffer (see recipe)

4.30.4

Supplement 21 
G418 (APPENDIX 1K)

Gancyclovir (GANC)

Freezing medium (see recipe)

Digestion buffer (see recipe)

Saturated $\mathrm{NaCl}$ (see recipe)

$1 \%$ agarose gel (APPENDIX IN)

Tissue culture hood

Gelatin-coated tissue culture plates (CPMB UNIT 23.3): 100-mm plates and 24-well microtiter plates

4-mm electroporation cuvettes

Pipet tips, sterilized by autoclaving

Nylon membrane

Additional reagents and equipment for subcloning DNA (see CPMB UNIT 3.16 and APPENDIX $1 A$ in this manual), restriction enzyme digestion (APPENDIX $1 M$ ), phenol/chloroform extraction of DNA (APPENDIX $1 G$ ), agarose gel electrophoresis (APPENDIX 1N), electroporation (APPENDIX 1E), ES cell culture (APPENDIX 3B), stable transformation using selective medium (see CPMB UNIT 9.5 and APPENDIX $1 \mathrm{~A}$ in this manual), and Southern blotting and hybridization (see CPMB UNITS $2.9 \& 2.10$ and APPENDIX $1 A$ in this manual)

NOTE: All tissue culture incubations should be performed in a humidified $37^{\circ} \mathrm{C}, 5 \% \mathrm{CO}_{2}$ incubator unless otherwise noted.

\section{Create a replacement construct}

1. Select a portion of the target gene to include in the construct and a separate portion of the target gene to use as a probe for hybridization of Southern blots to identify cells in which homologous recombination has occurred (see step 19).

It should contain a rare restriction site within an exon encoding an important region of the protein (or an exon upstream of such a region) that is ideally flanked by $>1 \mathrm{~kb}$ of target gene DNA on each side (most constructs are made with $2 \mathrm{~kb}$ ). The rate of homologous recombination may increase with increasing lengths of homologous DNA up to $15 \mathrm{~kb}$.

2. Construct a clone in a plasmid vector (see CPMB UNIT 3.16) such that the neo gene interrupts the gene of interest, leaving regions of homology on either side of the neo gene. Include a thymidine kinase $(T K)$ gene in the replacement construct outside the regions of homology (Fig. 4.30.4).

This construction can be accomplished by either adding the neo and TK sequences to the subcloned homologous sequences or by adding regions of homologous sequences to a plasmid already containing the neo and TK genes (e.g., pNTK; see Fig. 4.30.1).

3. Digest the construct DNA with a restriction enzyme to linearize (APPENDIX 1M).

Linearize the construct DNA so that the plasmid vector sequences remain attached to the $T K$ gene. This will help preserve the activity of TK gene if any loss of DNA sequence occurs during random insertion of the construct into the genome.

4. Purify and sterilize the digested construct DNA by phenol/chloroform extraction (APPENDIX 1G).

5. Precipitate the DNA by adding 2 vol of $95 \%$ ethanol and microcentrifuging $30 \mathrm{sec}$. Using sterile technique in a tissue culture hood, remove the supernatant and allow the pellet to air dry until only slightly moist.

6. Dissolve the pellet in $100 \mu \mathrm{l}$ sterile water. Check for complete digestion and estimate DNA concentration by electrophoresis on an agarose gel (APPENDIX IN).

Gene Cloning, Expression, and Mutagenesis

\subsection{5}

Supplement 21 
A

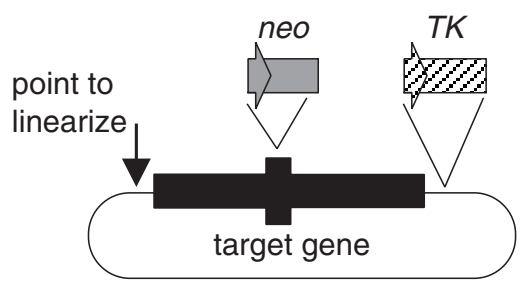

B

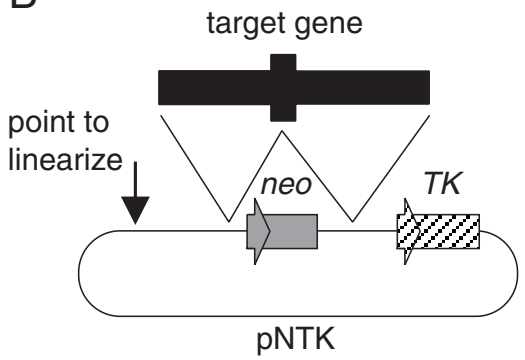

Homologous sequences

construct and target gene
Nonhomologous sequences

positive selectable marker

target gene

negative selectable marker $\square$

vector

promoter

Figure 4.30.4 Two strategies to create a replacement construct. In method $\mathbf{A}$ the target gene fragment is subcloned into a plasmid vector, then $\mathrm{P}_{\mathrm{PGK}}$-neo is inserted into a rare restriction enzyme site in the target-gene fragment and $\mathrm{P}_{\mathrm{PGK}}$-TK is inserted into the plasmid vector near the target gene. In method $\mathbf{B}$ the target-gene fragment is cleaved into two pieces that are subcloned into the polylinker sites of pNTK (see Fig. 4.30.1). Note that the relative orientation of homologous fragments in the construct must retain that found in the target gene.

\section{Transfect construct and select ES cells}

7. Culture ES cells in ES/LIF medium (APPENDIX 1B). Passage cells every 2 to 3 days by seeding a $100-\mathrm{mm}$ gelatin-coated tissue culture plate with $1-2 \times 10^{6}$ cells/plate.

Leukemia inhibitory factor (LIF) prevents ES cells from differentiating.

Some investigators suggest passaging cells at a higher density if blastocyst injection of the cells (CPMB UNIT 23.4) is planned (e.g., $1.5 \times 10^{6}$ cells per $25-\mathrm{cm}^{2}$ flask). A detailed description of culture techniques for ES cells is found in CPMB UNITS $23.2 \& 23.3$.

8. Harvest $\sim 5 \times 10^{6}$ to $1 \times 10^{7}$ cells by adding trypsin/EDTA and incubating for $\sim 5 \mathrm{~min}$ until cells are freed from the plate surface. Dissociate to single cells by pipetting up and down five to ten times. Add $5 \mathrm{ml}$ ES medium. Pellet cells and resuspend the cell pellet in $1 \mathrm{ml}$ electroporation buffer in the same tube.

Typically, $1 \times 10^{7}$ cells can be obtained from a near-confluent 100-mm tissue culture plate.

9. Add 1 pmol linearized, sterile construct DNA from step 6.

10. Electroporate the mixture at $450 \mathrm{~V}$ and $250 \mu \mathrm{F}$ in a 4-mm electroporation cuvette (APPENDIX 1E). Incubate $10 \mathrm{~min}$ at room temperature.

Many electroporation conditions can be used with ES cells (APPENDIX IE).

Production of a Heterozygous Mutant Cell Line

11. Plate cells in ES medium at $\sim 2 \times 10^{6}$ cells per 100 -mm gelatin-coated tissue culture plate. Incubate $24 \mathrm{hr}$.

12. Begin selection (see CPMB UNIT 9.5) by changing ES medium to ES/LIF medium and adding G418 to $0.2 \mathrm{mg} / \mathrm{ml}$ and GANC to $2 \mu \mathrm{M}$ (final).

\subsection{6}


13. Continue incubation, changing medium daily using ES/LIF medium and adding G418 $(0.2 \mathrm{mg} / \mathrm{ml}$ final) and GANC ( $2 \mu \mathrm{m}$ final $)$, until single, isolated colonies are visible (typically 1 week after electroporation). Remove an individual colony from the plate using an autoclaved pipet tip, and place in a 35- $\mu 1$ drop of trypsin/EDTA for 5 min. Pipet up and down about five times to dissociate cells. Transfer cells to a well of a gelatin-coated 24-well microtiter plate containing $1 \mathrm{ml} \mathrm{ES/LIF} \mathrm{medium.}$

14. Incubate until colonies are visible, but the cells are not differentiating (typically 3 to 4 days). Passage half of the cells to a well of a clean gelatin-coated 24-well microtiter plate. Add the remaining cells to $0.5 \mathrm{ml}$ freezing medium and place at $-70^{\circ} \mathrm{C}$. Freeze overnight, then transfer to liquid nitrogen.

Undifferentiated cells grow in smooth, round colonies. Differentiated cells are flatter with distinct intercellular boundaries.

Proceed immediately to step 15 after placing half the cells in the freezer.

\section{Screen for homologous recombinants}

15. Incubate ES cells in 24-well microtiter plate (step 14) to near confluence (usually 2 to 3 days).

Because it is not critical to prevent differentiation of the ES cells at this stage, LIF can be omitted from the culture medium; however, the presence of LIF may help to maintain cell growth.

16. Add $300 \mu \mathrm{l}$ digestion buffer to each well. Transfer well contents to a $1.5-\mathrm{ml}$ microcentrifuge tube, and incubate overnight at $55^{\circ} \mathrm{C}$.

17. Add $150 \mu \mathrm{l}$ saturated $\mathrm{NaCl}$ and vortex vigorously (the solution will turn milky white). Add 2 vol of $95 \%$ ethanol (the solution will turn clear except for precipitated DNA).

Some investigators precipitate the DNA using 2 vol ethanol (or 1 vol isopropanol) without adding salt. However, the DNA pellet resuspends more easily if salt is added.

18. Resuspend DNA pellet in $50 \mu \mathrm{l}$ water. Determine DNA concentration by measuring the absorbance at $260 \mathrm{~nm}$ (APPENDIX 1K).

19. Digest $10 \mu \mathrm{g}$ DNA (or $10 \mu \mathrm{l}$ if DNA concentration was not determined) with the appropriate restriction enzyme (APPENDIX $1 N$ ).

20. Fractionate the digested DNA on a $1 \%$ agarose gel (CPMB UNIT 2.5A). Transfer to a nylon membrane, and hybridize by Southern blotting (see CPMB UNITS $2.9 \& 2.10$ ) to the target-gene hybridization probe chosen in step 1 to distinguish the unaltered target gene from a target gene that has undergone homologous recombination.

21. Select ES cell colonies that show two hybridizing fragments of approximately equal intensity - one fragment of the predicted size for the unaltered target gene and one fragment of the predicted size for a target gene that has undergone homologous recombination. If the two fragments are of unequal hybridization intensity, the cell population may not be clonal. Freeze cells and store in liquid nitrogen.

22. If desired remove selectable markers that are flanked by loxP sites by transient expression of Cre (see Support Protocol).

Gene Cloning, Expression, and Mutagenesis

\subsection{7}

Supplement 21 


\section{TRANSIENT EXPRESSION OF CRE FOR RECOMBINATION}

Removal of sequences between the lox sites is accomplished by transient expression of Cre recombinase. If flanking lox sites are present in both alleles, Cre will recombine both alleles as efficiently as one. If selectable markers are between lox sites (as in Fig. 4.29.6), then sensitivity to selection media (e.g., containing G418) will be restored.

Additional Materials (also see Basic Protocol)

Cre expression plasmid using a promoter giving high expression levels in ES cells (e.g., pMC1 or pPGK)

$12.5 \mathrm{mg} / \mathrm{ml}$ 5-fluorocytosine in PBS (if selecting against CD), sterile

1. Expand the homologously recombined clones obtained using the Basic Protocol by culturing and harvesting ES cells (see Basic Protocol, steps 7 and 8).

2. Prepare Cre expression plasmid DNA using the same procedure as for the original targeting vector (see Basic Protocol, steps 4 to 6).

Do not linearize the DNA, as this will increase the probability of genomic integration.

3. Use 1 to 2 pmol of this DNA to transfect the expanded ES cell clones (see Basic Protocol, step 10).

Transfecting more DNA will most likely increase expression; however, it also increases the probability of integration.

4. Plate cells at a lower density than for the original targeting (since survival is expected to be higher).

The target is the number of clones per plate that will allow convenient colony picking. If no selection is to be performed, plating at a few hundred electroporated cells per 100-mm plate is a reasonable starting point. A range of dilutions should be plated (at least to a few thousand per plate), since the exact survival is not accurately predictable and plating at low density will decrease survival. If the negative selectable marker cytosine deaminase $(C D)$ is used, then plate at 1,000 to 10,000 cells per 100-mm plate, since higher densities will give complete killing due to a neighbor selection effect. The number of surviving colonies will depend on the frequency of recombination.

5. Continue to culture cells, replacing medium daily with fresh ES/LIF medium. If selecting against $\mathrm{CD}$, include $250 \mu \mathrm{g} / \mathrm{ml} \mathrm{5-fluorocytosine} \mathrm{(from} 12.5 \mathrm{mg} / \mathrm{ml} \mathrm{stock}$ ) in the medium.

6. Screen colonies for loss of the selectable marker (Cre-induced recombination) by Southern analysis (see Basic Protocol, steps 14 to 21).

Although Cre-construct integration is an unlikely event, the clones for injection can also be screened for presence of Cre by reprobing the Southern blots or by PCR.

\section{REAGENTS AND SOLUTIONS}

Use deionized, distilled water in all recipes and protocol steps. For common stock solutions, see APPENDIX 2A; for suppliers, see SUPPLIERS APPENDIX.

\section{Digestion buffer}

$20 \mathrm{mM}$ Tris. $\mathrm{Cl}, \mathrm{pH} 8.0($ APPENDIX $2 A)$

$10 \mathrm{mM} \mathrm{NaCl}$

$10 \mathrm{mM}$ EDTA

$0.5 \%(\mathrm{w} / \mathrm{v})$ sodium dodecyl sulfate (SDS)

Store indefinitely at room temperature

Add $1 \mathrm{mg} / \mathrm{ml}$ proteinase $\mathrm{K}$ just before use 
$20 \mathrm{mM}$ HEPES, $\mathrm{pH} 7.3$

$137 \mathrm{mM} \mathrm{NaCl}$

$5 \mathrm{mM} \mathrm{KCl}$

$0.7 \mathrm{mM} \mathrm{Na}_{2} \mathrm{HPO}_{4}$

$6 \mathrm{mM}$ glucose

$0.1 \mathrm{mM}$ 2-mercaptoethanol (2-ME)

Store indefinitely at $4^{\circ} \mathrm{C}$

\section{ES medium}

Dulbecco's minimum essential medium (DMEM), high-glucose + pyruvate formulation, containing:

$15 \%$ FBS, heat-inactivated $1 \mathrm{hr}$ at $56^{\circ} \mathrm{C}$

$0.1 \mathrm{mM}$ 2-mercaptoethanol (2-ME)

$20 \mathrm{mM}$ HEPES, pH 7.3 (optional)

DMEM containing $4500 \mathrm{mg} /$ liter D-glucose and pyruvate can be obtained from Life Technologies.

A detailed description of culture conditions for embryo stem cells has been presented by Robertson (1987).

\section{ES/LIF medium}

ES medium (see recipe) containing $1000 \mathrm{U} / \mathrm{ml}$ leukemia inhibitory factor (LIF; Life Technologies). Store $\leq 1$ week at $4^{\circ} \mathrm{C}$.

Conditioned medium from a CHO cell line overproducing LIF (Genetics Institute) can also be used at a dilution of 1:1000. An alternative to LIF for preventing differentiation of ES cells is to grow them on feeder layers of irradiated mouse embryo fibroblasts (MEF) in ES medium. Some investigators add $20 \mathrm{mM}$ HEPES (pH 7.3) to culture medium.

\section{Freezing medium}

DMEM, high-glucose + pyruvate formulation, containing:

$10 \% \mathrm{FBS}$ (Hyclone), heat-inactivated $1 \mathrm{hr}$ at $56^{\circ} \mathrm{C}$

$10 \%(\mathrm{v} / \mathrm{v})$ dimethylsulfoxide (DMSO)

$20 \mathrm{mM}$ HEPES, $\mathrm{pH} 7.3$ (optional)

Store at $-20^{\circ} \mathrm{C}$

\section{Saturated $\mathrm{NaCl}$}

Add $\mathrm{NaCl}$ to distilled $\mathrm{H}_{2} \mathrm{O}$ until no more dissolves ( $\left.\sim 6 \mathrm{M}\right)$. Some solid $\mathrm{NaCl}$ should remain; decant solution for use. Store indefinitely at room temperature.

\section{COMMENTARY}

\section{Background Information}

See UNIT 4.29 for an overview of gene targeting by homologous recombination.

Although homologous recombination has been used by yeast geneticists for some time, it has only recently been shown to occur in somatic mammalian cells. It was first demonstrated between exogenously introduced DNA sequences (Folger et al., 1982) and later between an exogenously introduced DNA construct and an endogenous gene (Smithies et al., 1985).

The mechanism of homologous recombination is not well understood but a number of characteristics are known. Homologous recombination occurs more readily if the construct has free ends, rather than being circular (Wong and Capecchi, 1987). The rate of homologous recombination does not depend on the number of targets in the genome-at least when the target is present as tandem repeats of a dihydrofolate reductase $(D H F R)$ amplified gene (Zheng and Wilson, 1990).

Initially, homologous recombination in mammalian cells was studied by introducing a mutated neo or $T K$ gene, then restoring neo or $T K$ activity by correcting the mutation through homologous recombination (reviewed by Capecchi, 1989). This approach provided an easy method to detect homologous recombination.
Gene Cloning, Expression, and Mutagenesis

\subsection{9}


Embryonic stem (ES) cells and the related embryonic carcinoma (EC or EK) cells were first isolated and cultured in 1981 (Evans and Kaufman, 1981; Martin, 1981). They can give rise to a chimeric mouse when introduced into a normal blastocyst, which is then transferred into the uterus of a pseudopregnant foster mother. The ES cells contribute to all tissues of the chimeric mouse including the germ line (Bradley et al., 1984). Currently, ES cells, rather than EC cells, are used to produce chimeric mice, because the extent of chimerism and efficiency of germ line transmission is much higher with normal cells. Most ES cell lines used are derived from males because the karyotype of XY cells is more stable than that of XX cells and resulting chimeric male mice are easier to breed. Typically, the extent of the contribution of the ES cells to somatic tissues of the chimeric mouse is easily determined visually by choosing strains of mice for the sources of ES cells and blastocysts that have different coat colors.

\section{Critical Parameters}

The degree of homology between the construct and the target genome can have a dramatic effect on the rate of homologous recombination in two ways. First, homologous recombination requires stretches of exact DNA homology. The DNA used to construct the targeting vector must be from the same species as the cell in which the mutation is to be introduced. It should also be isogenic with the target cell (this is not absolutely required, but increases the probability of success). Because animal strains may differ just as individual outbred animals differ, there may be a mismatch of DNA on average every $500 \mathrm{bp}$. A single DNA mismatch is sufficient to dramatically decrease the rate of homologous recombination (Deng and Capecchi, 1992; teRiele et al., 1992). Mutations induced by making constructs using long PCR may similarly decrease homologous recombination rates.

Second, the rate of homologous recombination increases with increasing length of the homologous DNA sequence (within limits). The exact length of homologous DNA that gives the maximum recombination rate is controversial but may be as high as $15 \mathrm{~kb}$ (Deng and Capecchi, 1992; Hasty et al., 1991). Homology should also be $>1 \mathrm{~kb}$ for the shorter arm (most constructs have used $>2 \mathrm{~kb}$ ). Further, fidelity of recombination can be lower if the length of homology is $<1 \mathrm{~kb}$ (Thomas et al., 1992).
The parameters outlined here are meant to be guidelines for the design of constructs. For some target genes and constructs, more or less homology may be required. Nonisogenic DNA recombines easily for some genes. If homologous recombination is not obtained initially, the same construct should be retransfected into the ES cells, as the rate of homologous recombination can vary for unclear reasons. A second construct using a different region of the gene can also be used because different constructs of the same gene may recombine at different rates. If homologous recombination is occurring, but only at a low rate, screening pools of clones by the polymerase chain reaction (PCR) may enable one to identify homologous recombinants (Koller et al., 1991).

\section{Anticipated Results}

In most cases, constructs prepared following the above guidelines should give rise to a number of homologous recombinant clones in a single transfection. Typically the frequency of homologous recombinant clones to surviving clones is $1: 30$ to $1: 5$; however, the range of reported results is large: the ratio may be $\leq 1: 1000$, or homologous recombinants may even be in the majority.

The frequency of recombination reported in the literature varies from $1 \%$ to $16 \%$; in the authors' hands, it has sometimes been as high as $30 \%$.

\section{Time Considerations}

The entire procedure, from cloning to obtaining homologous clones, can take several months, depending on the difficulty in obtaining the construct. Once a construct is obtained, however, transfection and selection of clones takes $\sim 2$ weeks. Screening clones takes 2 to 3 days. Addition of a neo removal step will add $\sim 4$ weeks for expansion of clones, transfection, and rescreening.

\section{Literature Cited}

Bradley, A., Evans, M., Kaufman, M.H., and Robertson, E. 1984. Formation of germ-line chimaeras from embryo-derived teratocarcinoma cell lines. Nature 309:255-256.

Capecchi, M.R. 1989. Altering the genome by homologous recombination. Science 244:12881292.

Cheng, S., Fockler, C., Barnes, W., and Higuchi, R. 1994. Effective amplification of long targets from cloned inserts and human genomic DNA. Proc. Natl. Acad. Sci. U.S.A. 91:5695-5699.

Deng, C. and Capecchi, M.R. 1992. Reexamination of gene targeting frequency as a function of the 
extent of homology between the targeting vector and the target locus. Mol. Cell. Biol. 12:33653371.

Evans, M.J. and Kaufman, M.H. 1981. Establishment in culture of pluripotential cells from mouse embryos. Nature 292:154-156.

Folger, K.R., Wong, E.A., Wahl, G., and Capecchi, M.R. 1982. Patterns of integration of DNA microinjected into cultured mammalian cells: Evidence for homologous recombination between injected plasmid DNA molecules. Mol. Cell. Biol. 2:1372-1387.

Hasty, P., Rivera, P.J., and Bradley, A. 1991. The length of homology required for gene targeting in embryonic stem cells. Mol. Cell. Biol. 11:5586-5591.

Koller, B.H., Kim, H.-S., Latour, A.M., Brigman, K., Boucher, R.C. Jr., Scambler, P., Wainwright, B., and Smithies, O. 1991. Toward an animal model of cystic fibrosis: Targeted interruption of exon 10 of the cystic fibrosis transmembrane regulator gene in embryonic stem cells. Proc. Natl. Acad. Sci. U.S.A. 88:10730-10734.

Martin, G.R. 1981. Isolation of a pluripotent cell line from early mouse embryos cultured in medium conditioned by teratocarcinoma stem cells. Proc. Nat. Acad. Sci. U.S.A. 78:7634-8.

Milstone, D.S., Bradwin, G., and Mortensen, R.M. 1999. Simultaneous Cre catalyzed recombination of two alleles to restore neomycin sensitivity and facilitate homozygous mutations. Nuc. Acids Res. 27:e10.

Robertson, E.J. 1987. Embryo derived stem cell lines. In Teratocarcinomas and Embryonic Stem
Cells: A Practical Approach (E.J. Robertson, ed.) pp. 71-112. IRL Press, Oxford and New York.

Smithies, O., Gregg, R.G., Boggs, S.S., Koralewski, M.A., and Kucherlapati, R.S. 1985. Insertion of DNA sequences into the human chromosomal beta-globin locus by homologous recombination. Nature 317:230-234.

teRiele, H., Maandag, E.R., and Berns, A. 1992. Highly efficient gene targeting in embryonic stem cells through homologous recombination with isogenic DNA constructs. Proc. Nat. Acad. Sci. U.S.A. 89:5128-5132.

Thomas, K.R., Deng, C., and Capecchi, M.R. 1992. High-fidelity gene targeting in embryonic stem cells by using sequence replacement vectors. Mol. Cell. Biol. 12:2919-2923.

Wong, E.A. and Capecchi, M.R. 1987. Homologous recombination between coinjected DNA sequences peaks in early to mid-S phase. Mol. Cell. Biol. 7:2294-2295.

Yenofsky, R.L., Fine, M., and Pellow, J.W. 1990. A mutant neomycin phosphotransferase II gene reduces the resistance of transformants to antibiotic selection pressure. Proc. Nat. Acad. Sci. U.S.A. 87:3435-3439.

Zheng, H. and Wilson, J.H. 1990. Gene targeting in normal and amplified cell lines. Nature 344:170173.

Contributed by Richard Mortensen

University of Michigan

Medical School

Ann Arbor, Michigan
Gene Cloning, Expression, and Mutagenesis

4.30.11 